\title{
IDEOLOGÍA POLÍTICA Y PRÁCTICAS MEDIATIZADAS DE CONSUMO INFORMATIVO
}

\author{
Silvina Brussino \\ Ana Pamela Paz García \\ Hugo H. Rabbia \\ Débora Imhoff
}

\section{Resumen}

En el marco de una reflexión analítica sobre los medios masivos de comunicación como objetos y referentes ideológicos del posicionamiento político, se estudia la relación entre consumo mediático e ideología política. A nivel empírico, se aplica un cuestionario a 273 ciudadanos mayores de 18 años de Córdoba/Argentina, seleccionados por un muestreo no probabilístico según cuotas de género, edad y nivel socio-económico. Entre los principales hallazgos, se observa tanto una tendencia hacia un esquema de consumo concentrado que reproduce los parámetros de competencia impuestos por el propio mercado mediático, como diferencias significativas en materia de selectividad ideológica entre quienes se identifican con alguna dimensión progresista o de izquierda y quienes se auto-posicionan hacia la derecha o son identificados como conservadores.

Palabras clave: Ideología Política; Medios Masivos de Comunicación; Exposición Selectiva; Consumo Ideológico; Información Política.

\begin{abstract}
In the framework of an analytical reflection on the mass media as ideological objects and referents of the political positioning, it is studied the relationship between mediatic consumption and politica ideology. To an empirical level, it is applied a questionnaire to 273 citizens older than 18 years old of Córdoba/Argentina selected by a nonprobability sampling according to quotas of gender, age and socio-economical level. Among the main findings, it is observed a tendency towards a concentrated pattern of consumption wich reproduces the parameters imposed by the very competitive media market, as well as significant differences in ideological selectivity between those who identify with any progressive or left dimension and those self-positioned to the right or who are identified as conservative.
\end{abstract}

Keywords: Political Ideology; Mass Media; Selective Exposure; Ideological Consumption; Political Information.

\section{Introducción}

La ideología política (en adelante IP) aparece como un aspecto de vital importancia para la comprensión de los fenómenos sociales y políticos, al constituirse como "heurístico" (LAU y REDLAWSK, 2006; JOST, 2006; JOST, 


\section{DOSSIÊ OPINIÃO PÚBLICA, ELEIÇÕES E PARTICIPAÇÃO POLÍTICA NAS DEMOCRACIAS CONTEMPORÂNEAS}

FEDERICO y NAPIER, 2009; BRUSSINO et al., 2011) que permite a los ciudadanos simplificar su universo político y dotarse de identidad en el proceso.

Por un lado, la adecuación de la IP como reflejo de las orientaciones de los ciudadanos continúa siendo un tema ampliamente debatido al interior de la ciencia política en general, y dentro de la tradición norteamericana de estudios empíricos sobre comportamiento electoral, en particular. En sus investigaciones sobre el electorado americano, Converse (2006) encuentra que en los ciudadanos predomina un escaso reconocimiento de las orientaciones ideológicas, limitándose a las élites y las personas más sofisticadas políticamente el uso interpretativo activo de etiquetas y posicionamientos. En la misma línea, para Jacoby (1991) es generalmente baja en la práctica la habilidad del ciudadano promedio para elaborar el conflicto político representado por las etiquetas de posicionamiento izquierda versus derecha, en términos ideológicos abstractos y con la capacidad de relacionarlos respecto del propio sistema de creencias políticas. A esto se suma el hecho de que las categorías cognitivas que los individuos vinculan a dichas nociones pueden ser ampliamente distantes de lo que desde la literatura científica se entiende a priori, a la vez que reflejarían una gran heterogeneidad respecto a quienes se posicionan incluso en un mismo valor de la escala (ZECHMEISTER, 2006). Sin embargo, específicamente en el caso argentino estudios locales advierten los efectos de un creciente nivel de conocimiento de los ciudadanos sobre los posicionamientos ideológicos tradicionales (BRUSSINO et al., 2011). Así, mientras en 1988 casi la mitad de los encuestados de una muestra nacional no podían o no querían autoposicionarse ideológicamente (CATTERBERG y BRAUN, 1989), en 1999 un $40 \%$ de los ciudadanos argentinos no logró identificarse como de izquierda o de derecha (D'ADAMO y GRACÍA BEAUDOUX, 1999) y en 2003 , sólo un $12,8 \%$ de los cordobeses no pudo autoposicionarse y un $10 \%$ no quiso hacerlo (BRUSSINO, RABBIA y HÜG, 2003). Asimismo, teniendo en cuenta el posicionamiento ideológico de los partidos políticos se reconoce otro rasgo de atipicidad del caso argentino: la percepción relevada de sus posiciones ideológicas es similar entre unos y otros (CATTERBERG y BRAUN, 1989) y las diferencias ideológicas se expresan más "como divisorias internas de los grandes partidos" que como contrastes "entre ellos" (OSTIGUY, 1998 apud ALESSANDRO, 2009, p. 583). En esta dirección es posible entender ciertos fenómenos locales como por ejemplo, que el Partido Justicialista ("peronismo") contenga en su seno orientaciones que reflejan posiciones de uno a otro extremo del continuum derecha-izquierda, o que en los ciudadanos cordobeses convivan de forma paradójica representaciones sociales sobre el papel del estado de tipo bienetaristas y neoliberales (BRUSSINO, RABBIA y HÜG, 2003).

Por otra parte, el análisis psico-socio-político contextualizado de la IP se vincula con la teoría de la mediación social, en el marco de un interés por 
comprender "cómo asimilamos bienes de consumo por intermedio de mitos, opiniones, creencias, etc. y los incorporamos a nuestra cotidianidad" (TORO TAMAYO, 2008, p. 258). Así, el estudio de la IP cobra relevancia para la comprensión de experiencias sociales y expectativas culturales, considerando su papel de mediación social constitutiva de relaciones y contextos de interacción en los que se desenvuelven las personas. A nivel macrosocial, las ideologías constituyen lógicas operativas complementarias de los niveles interpersonal e intergrupal (NAFSTAD et al., 2007). García Canclini (1984) complejiza este abordaje, postulando que la ideología constituye una "elaboración más o menos autónoma a partir de la cual una clase se explica sus condiciones de vida" (1984, p. 12). Si bien está relacionada con sus condiciones objetivas, la ideología no posee un vínculo de determinación causal o unidireccionado $\mathrm{y}$, a nivel microsocial, las prácticas cotidianas de consumo cultural asumen una condición politizada e ideológica compleja.

En cuanto al consumo cultural, éste se convierte en un "acto político" (SENI-MEDINA, 2011) al legitimar una posición o estatus social, y más allá de su racionalidad económica, su práctica descansa sobre una "racionalidad sociopolítica interactiva" reflejada en productos, marcas y redes sociales. Portando entonces una dimensión identitaria significativa, esta participación segmentada en el consumo se produce y reproduce desde una interacción entre actitudes y comportamientos como fuerzas constitutivas de la opinión pública. Dicha opinión se constituye en "un proceso interactivo entre lo interno - personalidad, conocimientos y estructura de creencias - y lo externo - influencias del grupo social o medios de comunicación masiva" (MILBURN, 1994, p. 18 apud Seni-Medina, 2011, p. 131).

Específicamente, la relación entre IP y medios masivos de comunicación (en adelante MMC) resulta significativa tanto desde el estudio de las instancias y lógicas de su producción, como de sus contextos de recepción y apropiación.

En primer lugar, los MMC entendidos como "aparato ideológico de mediación social" (TORO TAMAYO, 2008) son espacios para la confrontación de ideologías, al difundir no sólo la IP de los grupos dominantes sino también la de grupos rivales (MORENO GARCÍA, 2007). De esta manera, el carácter estratégico de su poder simbólico se expresa en al menos dos sentidos: primero, como instancias prioritarias de circulación y difusión social de los frames o marcos ideológicos de las élites de poder (MORENO GARCÍA, 2007); segundo, como espacios de selección y visibilidad de los problemas políticos de cada sociedad, habilitando en sus agendas issues coyunturales sobre los cuales emergen posicionamientos ideológicos. En esta línea, Ellis y Stimson (2005) observan que la exposición cotidiana a las noticias se constituye en pre-requisito para la influencia de las ideologías dominantes. En su distinción de las funciones "operativas" y "simbólicas" de la IP, estos autores consideran que junto a la educación, el conocimiento y el interés político, la exposición mediática es un factor condicionante del auto-posicionamiento ideológico. 


\section{DOSSIÊ OPINIÃO PÚBLICA, ELEIÇÕES E PARTICIPAÇÃO POLÍTICA NAS DEMOCRACIAS CONTEMPORÂNEAS}

Otros estudios empíricos demuestran que las personas que no emplean activamente las etiquetas ideológicas tradicionales muestran una mayor dependencia de las pistas de etiquetación y posicionamiento que las élites políticas les transmiten a través de los MMC (DUFF, 2007).

En esta línea, en Argentina algunas investigaciones han abordado tanto la capacidad de los MMC para direccionar la atención social, definiendo y jerarquizando los problemas públicos dentro de sus agendas (D'ADAMO, FREIDENBERG y GARCÍA BEAUDOUX, 2000), como sus efectos cognitivos en la configuración de mapas mentales acordes con las condiciones de receptividad de los ciudadanos (APARICIO, 2005). Se destaca así la institucionalización de los MMC como "sistema de mediación en el conocimiento e interpretación de la realidad social" (PAZ GARCÍA, 2008, p. 198), proveedor tanto de la materia socialmente opinable como de los datos de su valoración pública dentro del espacio político. En este sentido, si bien la IP y los marcos mediáticos se observan interconectados - dado que el tratamiento de las noticias supone tomas de posición por parte de los MMC generando un "clima particular de opinión" (ALAMINOS, FRANCÉS y SANTACREU, 2005, p. 23) -, la aparición de nuevos medios interpela esta articulación. Holbert, Garrett y Gleason (2010) destacan el potencial de tales medios para convertir a los ciudadanos en fijadores de agenda (agenda setters) y no sólo receptores. Se trataría de pull media tales como blogs y foros, donde la publicación de contenidos es abierta a la participación, a diferencia de los push media (medios tradicionales) condicionados por un modelo verticalista y dominante de producción social de la información.

Un segundo aspecto que evidencia la importancia de estudiar la relación entre IP y MMC, surge de estudios que señalan que el consumo mediático se encontraría ideológicamente orientado. En ese sentido, Turner (2007) muestra el empleo de la IP como método de evaluación que anticipa las decisiones de exposición de las audiencias. Así, las personas emplean las etiquetas ideológicas atribuidas a las instituciones mediáticas como señales para reconocer el tipo de información ofrecida, con independencia de su contenido. Iyengar y Hahn (2009) por su parte, observan que el consumo mediático varía en función de la afinidad ideológica que las personas perciben con la fuente de información. Este patrón de selectividad ideológica en la exposición mediática se sostiene incluso cuando los consumidores incursionan en nuevos MMC como Internet. También Stroud (2008) ratifica estas tendencias y advierte que la selectividad ideológica se agudiza en contextos electorales, mostrando la importancia de las variables situacionales. Este debate se vincula con el problema de la mayor o menor selectividad en la exposición mediática (selectivity exposure to information), el cual encarna una amplia controversia en torno al paradigma de los efectos mínimos de la comunicación masiva ${ }^{1}$. En este sentido, se advierte que históricamente las

${ }^{1}$ Efectos mediáticos limitados al refuerzo de actitudes pre-existentes. 
investigaciones empíricas han tendido a desplazarse desde un énfasis en el estudio del mensaje hacia un interés por la recepción y reproducción social de la información.

Dentro de la Mass Communication Resarch como primera gran tradición de estudios psico-sociales en este campo, se destaca la figura del sociólogo Paul F. Lazarsfeld y sus estudios sobre el reforzamiento de actitudes. Frente al estudio de los efectos mediáticos directos, uniformes y a corto plazo (strong effects), Lazarsfeld cuestiona la idea de omnipotencia de los MMC y antepone la "teoría de los efectos limitados", centrada - más que en el cambio - en la idea de refuerzo de actitudes pre-existentes. Sus aportes marcan de este modo una ruptura con la sociología funcionalista de los MMC dominante en los años '50 (MATTELART y MATTELART, 1997, p. 30), que bajo la herencia de estudios previos en propaganda bélica imaginaba un receptor pasivo y fácilmente manipulable. Atendiendo a la mediación producida por las estructuras sociales, los estudios de Lazarsfeld y su equipo sobre los "grupos primarios" y la influencia de los "líderes de opinión" (hipótesis del flujo comunicativo en dos etapas o two-step flow $^{2}$ ), rompen con la idea de una opinión pública (OP) uniforme valorando la influencia de las redes sociales. Durante la segunda mitad del siglo XX, bajo el predominio de los estudios sobre las funciones de los MMC como sistema social, los estudios dirigidos por Lazarsfeld profundizan en las condiciones de la instancia de recepción, moviéndose hacia una sociología de las audiencias (PAZ GARCÍA, 2011). La obra de Joseph Klapper en los '60 emerge en este momento de cambio sustancial, donde surge un interés por los efectos de largo plazo, latentes e indirectos, que se desplaza de los efectos limitados a los efectos moderados y de los efectos persuasivos a los efectos cognitivos. Así, el concepto de "exposición selectiva" adelanta un paradigma reflexivo sobre los efectos negociados de los MMC, como discusión inacabada y que corre en paralelo a las investigaciones sobre IP, hasta entonces prioritariamente desarrolladas en base al estudio de procesos electorales como en el caso de los trabajos de Converse (2006) antes mencionados.

Klapper estudia la relativa estabilidad de las preferencias en las campañas electorales y las atribuye a una "tendencia de la gente a exponerse a aquellas comunicaciones masivas que estén de acuerdo con sus actitudes e intereses existentes" (KLAPPER, 1960 apud KINDER, 2003, p. 369) y

\footnotetext{
${ }^{2}$ Se refieren aquí básicamente dos estudios: "The People's Choice: How the Voter makes up his mind in a Presidential Campaign" centrado en el caso de las elecciones presidenciales estadounidenses de 1940 y publicado por Lazarsfeld junto a Bernard Berelson y Hazel Goudet en 1944, y "Personal Influence: The Part Played by People in the Flow of Mass communication" también elaborado sobre material electoral y publicado con E. Katz en 1955. Desde los datos aportados por estas investigaciones, los autores comprenden el flujo de comunicación masiva como proceso en dos etapas: "en el primer escalón están las personas relativamente bien informadas por estar directamente expuestas a los medios de comunicación"; en el segundo, las que los frecuentan menos y que "dependen de las otras para obtener información" (MATTELART y MATTELART, 1997, p. 35).
} 


\section{DOSSIÊ OPINIÃO PÚBLICA, ELEIÇÕES E PARTICIPAÇÃO POLÍTICA NAS DEMOCRACIAS CONTEMPORÂNEAS}

consciente o inconscientemente, evitar comunicaciones en sentido opuesto. Desarrollos posteriores discuten estas conclusiones desde evidencias empíricas diferentes y obteniendo resultados no concluyentes. Al respecto, se destacan los aportes de John Zaller a la comprensión del carácter contingente de la persuasión política. Para Zaller la dinámica de la OP se mueve "en relación con las alteraciones en la oferta de información provista por las élites" (ZALLER, 1992 apud KINDER, 2003, p. 373) y la efectividad políticopersuasiva de las comunicaciones mediáticas masivas dependería de dos competencias básicas de las audiencias, como son su nivel de información general sobre política (que involucra tanto la exposición como la comprensión de los contenidos comunicados) y el grado de consistencia con sus predisposiciones político-ideológicas. Por su parte, Norris (2004) intenta complejizar este planteo, superando el entrampamiento producido por las teorías sobre el malestar mediático, tendientes a subestimar otras bases institucionales e inter-subjetivas del comportamiento político-ideológico de consumo mediático. En base al estudio sistemático de un conjunto de encuestas tomadas en sociedades "post-industriales", Norris (2004) profundiza en el vínculo del conocimiento político, la confianza institucional y la participación ciudadana con el interés por la exposición a las noticias políticas. Al respecto, el autor advierte la existencia de un proceso interactivo entre estas condiciones de exposición de las audiencias y la estructura de la oferta mediática (predominio de noticias negativas, sensacionalismo, espectacularización, etc.). Se trataría de un "círculo virtuoso" (NORRIS, 2004) donde predomina el efecto de refuerzo de las actitudes previas: socializados desde una repetida exposición, los ciudadanos más interesados y conocedores de los temas políticos suelen ser activados por los contenidos difundidos por los MMC y los partidos o líderes políticos; mientras quiénes se muestran desinteresados o des-motivados tienden a des-atender las noticias políticas o bien atenderlas desde una base de desconfianza sobre sus fuentes. Así, el compromiso cívico se ve afectado por las disposiciones actitudinales hacia el consumo de información política, pero no puede responsabilizarse exclusivamente a los MMC o los partidos políticos por esta situación, debiendo considerarse el impacto de otros múltiples factores sociales e institucionales.

Considerando que los antecedentes recopilados indican que los ciudadanos tienden a orientar ideológicamente su consumo mediático, dentro del recorrido trazado resta explicar cuáles son los procesos psico-sociales subyacentes a los aspectos estructurales del consumo. Desde una perspectiva psico-social, el consumo mediático de información política ha sido abordado principalmente por tres grandes corrientes de explicación: primero, los abordajes de la teoría de la disonancia cognitiva; segundo, los estudios que retoman la teoría de la personalidad (personality traits); y tercero, las investigaciones sobre el consumo mediático como una forma de hábito o consumo ritualizado adquirido en ciertas prácticas sociales.

La tendencia a elegir informaciones políticas basada en un acuerdo 
ideológico anticipado ha sido vinculada por algunos autores con la Teoría de la Disonancia Cognitiva de Festinger (IYENGAR y HAHN, 2009; GRAF y ADAY, 2008; STEMPEL, 1961). Dicha teoría argumenta que las personas buscarían información con la que esperan coincidir (D'ALESSIO y ALLEN, 2007; GARRET, 2006) y/o evitarían tomar contacto con aquella que anticipadamente resultaría contraria a sus puntos de vista (CASE et al. 2005) ${ }^{3}$, como manera de disminuir la disonancia. Garret (2006) reflexiona sobre este hecho, planteando que si los ciudadanos se limitaran a exponerse a informaciones a fin de reforzar creencias y actitudes previas, esto tendría impactos severos sobre la discusión y la tolerancia política. En contraposición, otros estudios afirman que evitar la disonancia es un motivo relativamente débil en la adquisición de información (IYENGAR y HAHN, 2009) y que esta teoría no explica las diferencias en la elección del tipo de medio (SCHWEIGER, 2006). Asimismo, existen dudas acerca de si las actitudes políticas previas que guían el consumo existían realmente con anterioridad, así como sobre el nivel de disonancia efectivamente experimentado por las personas (SEARS y FREEDMAN, 1967).

Por su parte, un abordaje complementario y no excluyente del anterior, es el de la Teoría de la Personalidad. Gerber et al. (2011) constatan que los rasgos de personalidad (personality traits) son predictores significativos del interés político y el consumo de información política. La apertura - grado en que una persona necesita variedad y estimulación intelectual - y la estabilidad emocional - caracterizada por niveles bajos de ansiedad - están asociadas con el consumo informativo y el conocimiento político. En esa línea, las personas con mayor apertura estarían predispuestas a las experiencias novedosas y desafiantes, siendo más proclives a sostener puntos de vista progresistas y sintiéndose más atraídas hacia el intercambio de ideas políticas. A su vez, los resultados muestran que estas personas son más proclives a emplear Internet como fuente de información y a preferir las noticias nacionales a las locales. Al respecto, Federico y Goren (2009) destacan que existen apropiaciones diferenciadas de las IPs propuestas por las élites, según las "motivaciones epistémicas" de las audiencias necesidades relacionadas con la adquisición y uso social de la información. Así, las personas cuyas motivaciones epistémicas son cerradas - baja necesidad de cognición, alta necesidad de cierre - serían proclives a adoptar posiciones de derecha. Esta predisposición aparece con más fuerza en personas familiarizadas con el discurso ideológico de las élites, quienes logran unir su motivación epistémica con la orientación ideológica "apropiada", mientras aquellos que carecen de esta comprensión eligen más azarosamente.

\footnotetext{
3 Para Garret (2006) ambas conductas son diferentes. Si bien la búsqueda de información coincidente con el propio punto de vista podría producir convicciones políticas más profundas, no implica necesariamente una reducción en la exposición a informaciones políticas contrarias.
} 


\section{DOSSIÊ OPINIÃO PÚBLICA, ELEIÇÕES E PARTICIPAÇÃO POLÍTICA NAS DEMOCRACIAS CONTEMPORÂNEAS}

Una tercera perspectiva de corte más culturalista, enfatiza la importancia de los hábitos de consumo de información política, adquiridos en el marco de los procesos de socialización. El consumo mediático no sería producto de un análisis racional, motivado o planeado, sino el resultado de rutinas cotidianas. Algunos autores sugieren entenderlo como una práctica ritual (CANTÚ, 2006) en la que se reafirman significados sociales y que colabora con el sentimiento de seguridad ontológica. De este modo, el consumo local se construye como "lazo de unión con los próximos, como una forma de reconstruir diariamente el vínculo de pertenencia a la comunidad" (CANTÚ, 2006, p. 5). No obstante, Christensen (2006) advierte que el consumo mediático no es un ritual en sí mismo sino que forma parte de otros hábitos (como los familiares) y otros autores consideran que estas prácticas estarían influidas por emociones (MCQUAIL, 2001) o bien guiadas por procesos automatizados y no basadas en actitudes o intenciones (AARTS, VERPLANKEN y VAN KNIPPENBERG, 1998).

Una última referencia debe hacerse sobre las elecciones de consumo mediático en relación con el tipo de medio utilizado para informarse políticamente. Garret y Danzinger (2011) en Estados Unidos, obtienen resultados que indican que la televisión es el medio más consumido y que los usuarios de Internet con frecuencia son personas más jóvenes, con mayores ingresos económicos, mayor nivel educativo y una ideología partidaria más definida. Complementariamente, otros autores constatan que en España la prensa es el medio más consumido por los sectores con mayor nivel educativo, poder adquisitivo e interés político. Esto podría vincularse con la tesis de la distancia social en el acceso a la información: "a medida que ascendemos por los estratos de la estructura social, el consumo de información aumenta y se diversifican las fuentes que nutren el conocimiento político" (JEREZ, SAMPEDRO y BAER, 2000, p. 6). Por su parte, Fara (2004) indica que si bien en gran parte de la región latinoamericana la lectura de diarios es insignificante, este medio tradicional continúa detentando el mayor poder en fijar la agenda informativa. Cabe destacar que en Argentina los diarios han mantenido un histórico poder de fijación de la agenda informativa (FARA, 2004; MARTÍNEZ PANDIANI, 2007), principalmente a través de diarios nacionales editados en la capital del país y a pesar del constante crecimiento de MMC digitales que muestran un mayor dinamismo en sus pautas de edición y circulación. Finalmente, respecto del género, estudios muestran un consumo diferencial entre varones y mujeres, donde los primeros se caracterizan por consumir más información política. A su vez, las mujeres consumirían más noticias vinculadas con la comunidad (KNOBLOCH-WESTERWICK, BRÜCK y HASTALL, 2006), mientras los hombres preferirían aquéllas relativas al país y el mundo (LOZANO RENDÓN, 2003). 


\section{Objetivos de investigación y características de la población estudiada}

En el presente estudio se analiza la relación entre el consumo mediático de información política y la IP. Al respecto, un aporte de relevancia lo constituye el complejizar el clásico abordaje de la IP por la vía del autoposicionamiento, proponiendo una medición de posicionamientos subyacentes en torno a diversos tópicos socio-políticos actualmente en debate en la sociedad argentina. Considerando las tesis principales emergentes en la literatura sobre el tema antes expuesta, se profundiza entonces en la estructuración social y psico-política del consumo mediático en Córdoba y desde el abordaje de este caso, se propone comprobar la existencia de asociaciones significativas dentro de las siguientes hipótesis:

En consonancia con la tesis del consumo selectivo, el autoposicionamiento ideológico se asocia con las preferencias de consumo mediático.

Las orientaciones ideológicas atribuidas a los medios preferidos se relacionan con los posicionamientos ideológicos subyacentes sobre temas de política pública, reflejando patrones diferenciados de consumo mediático entre conservadores y progresistas.

Las características sociodemográficas (edad, sexo, nivel socioeconómico, nivel educativo) inciden sobre las preferencias mediáticas, mediando motivos tanto sociales como individuales en el marco de rutinas de consumo mediático.

En cuanto a la ciudad de Córdoba como territorio donde se desarrolla el trabajo de campo, cabe sintentizar aquí algunas de sus particularidades idiosincráticas antes de avanzar en las consideraciones metodológicas y los principales resultados. Lejos de localismos insustanciales pero también tomando distancia de un pensamiento teórico-metodológico único para todos los horizontes del espacio social, razones socio-demográficas y sociohistóricas refuerzan la importancia de advertir tales particularidades. Desde esta distinción, asimismo se espera contribuir a equilibrar el predominio internacional de investigaciones científico-sociales centradas en los acontecimientos de la capital del país, como escenario privilegiado de la política argentina.

Ubicada en la región mediterránea y siendo la segunda ciudad argentina con mayor volumen de población ${ }^{4}$, Córdoba se ha destacado por su carácter de ciudad "frontera" marcada por una tensión entre lo innovador y lo reaccionario (TCACH, 2004). Esta "bifrontalidad" emerge con particular fuerza entre 1945-1955, período donde Córdoba se convierte en "bastión del

\footnotetext{
${ }^{4}$ La ciudad de Córdoba cuenta con 1.330 .023 habitantes según datos provisionales del último censo nacional oficial (INDEC, 2010), siendo el segundo distrito urbano más poblado del país.
}

REVISTA DEBATES, Porto Alegre, v. 5, n. 2, p. 13-40, jul.-dez. 2011. 


\section{DOSSIÊ OPINIÃO PÚBLICA, ELEIÇÕES E PARTICIPAÇÃO POLÍTICA NAS DEMOCRACIAS CONTEMPORÂNEAS}

radicalismo argentino" (TCACH, 1991, p. 11), gestándose en esta ciudad la oposición católica nacional al peronismo desde los intentos golpistas de 1945 hasta la conjunción cívico-militar que lo derrocaría 10 años más tarde. Bajo un tradicionalismo con frecuencia acusado de intransigencia, Córdoba aparece proyectada sobre la historia nacional como una suerte de "Ciudad-Estado", donde se jugaba el éxito o fracaso de los gobiernos nacionales. Asimismo, la Reforma Universitaria que emerge a principios del siglo XX, y el "Cordobazo", como expresión del movimientismo obrero-sindical y estudiantil de los 60's, son sólo algunos de los hechos que caracterizan su matriz contradictoria.

A la luz de estas configuraciones ideológicas que atraviesan la identidad de la cultura política cordobesa contemporánea, cabe destacar el predominio entonces de cierta pretensión de autonomía como característica de la proyección de Córdoba a nivel político nacional. Sin embargo, con el paso del tiempo dicha especificidad ha mostrado una moderación de su radicalismo ideológico y tendencias polarizantes, generando un todavía complejo y no menos contradictorio núcleo valorativo de posicionamientos políticos, cuya interpretación se mantiene como una constante desafiante para el presente trabajo.

\section{Metodología}

Dentro de la ciudad de Córdoba, los participantes del estudio fueron seleccionados a través de un muestreo estratificado por cuotas (LOHR, 2000), con un intervalo de confianza del $95,5 \%$ y un margen de error de 6 puntos porcentuales. Con esta modalidad se buscó garantizar que en la muestra se replicaran las características demográficas de la población. Adoptando como criterio las proporciones estimadas por el Instituto Nacional de Estadísticas y Censos (INDEC), se establecieron cuotas de edad, género y nivel socioeconómico. El trabajo de campo fue realizado entre los meses de abril y junio de 2010. Así, la muestra quedó conformada por 273 personas con edades comprendidas entre los 18 y 65 años ( $18-25$ años $=21 \%, 26-35$ años $=30 \%, 36-45$ años $=20 \%, 46-55$ años $=16 \%$ y $56-65$ años $=13 \%$ ); $51 \%$ fueron mujeres y $49 \%$ hombres; $52 \%$ pertenecían a nivel socioeconómico medio, medio superior y alto, $22 \%$ a bajo superior, $16 \%$ a bajo inferior y $10 \%$ a marginal.

Para evaluar la variable Ideología Política se adoptaron dos modalidades de medición. Por un lado, se tomó en consideración el autoposicionamiento ideológico. Para ello, se pidió a los participantes autoidentificarse con una etiqueta de IP dentro de un arco gradual de alternativas entre los extremos (1) "Totalmente de izquierda" y (5) "Totalmente de derecha", siendo el (3) equivalente a la opción "Centro". Fuera de este espectro espacial de auto-posicionamiento ideológico, se contemplaron las opciones "No puede auto-ubicarse", "Ninguna", "No contesta" y las categorías 
alternativas "Apolítico" e "Independiente" ${ }^{5}$, trabajadas en estudios previos sobre las modalidades de vinculación ciudadana con el sistema políticopartidario. Dado que los resultados de esta primera medición (autoposicionamiento) de la variable IP, son retomados más adelante por el presente trabajo directamente en su cruzamiento contingente con el consumo de cada uno de los MMC estudiados, a continuación y antes de profundizar en el análisis de dichos cruzamientos, se incluye la distribución de frecuencias que cada una de las categorías de la variable presentó en términos generales.

Tabla 1 - Auto-posicionamiento ideológico por categorías

\begin{tabular}{l|c|c|c}
\hline $\begin{array}{c}\text { Auto-posicionamiento } \\
\text { Categorías de }\end{array}$ & Frecuencia & Porcentaje & $\begin{array}{c}\text { Porcentaje } \\
\text { acumulado }\end{array}$ \\
\hline Totalmente de Izquierda & 30 & 11,0 & 11,0 \\
\hline Centro izquierda / algo de izquierda & 50 & 18,3 & 29,3 \\
\hline Centro & 84 & 30,7 & 60,0 \\
\hline Centro derecha / algo de derecha & 37 & 13,6 & 73,6 \\
\hline Totalmente de Derecha & 18 & 6,6 & 80,2 \\
\hline Apolítico & 4 & 1,5 & 81,7 \\
\hline Independiente & 3 & 1,1 & 82,8 \\
\hline No puede autoubicarse & 27 & 9,9 & 92,7 \\
\hline Ninguna & 18 & 6,6 & 99,3 \\
\hline No contesta & 2 & 0,7 & 100,0 \\
\hline Total de casos & 273 & 100,0 & \\
\hline Fue
\end{tabular}

Fuente: Elaboración propia en base a Encuesta 2009/2010 Proyecto PID 2008 SeCyT Córdoba.

Por otro lado, se aplicó la Escala de Ideología Política (BRUSSINO et al., 2011) que consta de 22 ítems situacionales sobre tópicos específicos (política social, economía, sexualidad, drogas, religión, medioambiente y nacionalismo) en función del eje intervención - no intervención del Estado. Estos ítems se distribuyen en cuatro sub-escalas: conservadurismo sexual religioso con 7 ítems, progresismo multiculturalista con 7 ítems, conservadurismo represivo nacionalista con 5 ítems, y progresismo garantista con 3 ítems. Cada ítem es respondido y cuantificado de acuerdo a una escala de cinco puntos, entre (1) "Nada de acuerdo" y (5) "Totalmente de acuerdo". Las cuatro sub-escalas presentaron valores adecuados de fiabilidad en función

\footnotetext{
5 Tanto la categoría "apolítico" como "independiente" (aquí utilizada en sentido análogo a la de "apartidario"), son tipologías desarrolladas en estudios previos (VAGGIONE y BRUSSINO, 1997) sobre el grado de vinculación con el sistema de partidos y el nivel de interés en la política, como conceptos centrales en la caracterización de las modalidades de participación ciudadana. Con el término "apolíticos" se indican aquellos sectores de la población que combinan una desvinculación respecto de dicho sistema con un desinterés por la dinámica política, mientras los "independientes" o "apartidarios" representan a "quiénes a pesar de no estar identificados partidariamente, tienen interés por la política y poseen los recursos socioeconómicos mínimos que permiten un involucramiento y comprensión de la dinámica política" (VAGGIONE y BRUSSINO, 1997, p. 308).
} 


\section{DOSSIÊ OPINIÃO PÚBLICA, ELEIÇÕES E PARTICIPAÇÃO POLÍTICA NAS DEMOCRACIAS CONTEMPORÂNEAS}

del valor del estadístico Alfa de Cronbach $^{6}$ (conservadurismo sexual y religioso a .77; progresismo económico multiculturalista a .71; conservadurismo represivo nacionalista a .70; progresismo garantista a .66). A continuación se detallan los ítems incluidos dentro de cada una de las mencionadas subescalas.

Tabla 2 - Ítems y cargas factoriales de sub-escalas conservadoras y progresistas

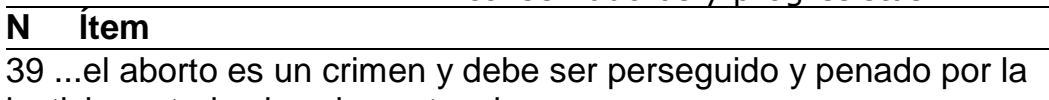
justicia en todas las circunstancias.

33 ...los políticos deberían escuchar más los reclamos y propuestas de la Iglesia Católica sobre los problemas que atraviesa la sociedad. 31 ...está bien que el Estado sostenga económicamente a la Iglesia Católica.

6 ...el Estado debería prohibir la exhibición pública de obras de arte que sean ofensivas a la moral o religión de determinados grupos de personas.

48 ...sólo los padres tienen derecho a enseñar a sus hijos temas relacionados con la sexualidad; el colegio no debería intervenir en estas cuestiones.

43 ...la educación sexual en jóvenes es peligrosa porque los motiva a una iniciación sexual temprana.

44 ...la ley no debería permitir a personas homosexuales dar clases en las escuelas.

27 ...en todas las escuelas se debería enseñar un idioma de nuestros pueblos indígenas para aprender a apreciar su herencia cultural.

5 ...el Estado debería hacer lo posible por evitar la concentración de medios de comunicación en pocas manos, y asegurar así la pluralidad de expresión.

4 ...el Estado debería garantizar a todos los ciudadanos acceder por igual al teatro, cine y demás producciones culturales locales. 26 ...el Estado debería otorgarles tierras a las comunidades indígenas que habitan en el país para que puedan autogobernarse. 15 ...la propiedad de la tierra debe ser de quien la trabaje. 20 ...el Estado debería poner límites a la producción de soja en el territorio nacional a los fines de frenar el monocultivo y los efectos de desertización de los suelos.

9 ...el Estado debería promover campañas de concientización sobre el consumo responsable de sustancias como la marihuana.

\begin{tabular}{c|c|c|c|c}
\hline $\mathbf{1}$ & $\mathbf{2}$ & $\mathbf{3}$ & $\mathbf{4}^{*}$ \\
\hline, 749 & & & \\
\hline, 651 & & & \\
\hline, 631 & & & \\
\hline, 481 & & & \\
\hline, 510 & & & \\
\hline, 324 & & & \\
\hline &, 732 & & \\
\hline &, 628 & & \\
\hline &, 621 & & \\
\hline &, 603 & & \\
\hline &, 519 & & \\
\hline &, 518 & & \\
\hline & & & \\
\hline & & & \\
\hline & & & \\
\hline
\end{tabular}

${ }^{6}$ Se trata de un coeficiente útil para evaluar la precisión de escalas psico-métricas y otras técnicas de medición frecuentemente utilizadas en ciencias sociales. Sus valores oscilan entre 0 y 1 y se considera que existe una buena consistencia interna y un adecuado nivel de confiabilidad cuando el valor de alfa (a) es superior a 0,7 . 
35 ...la pena de muerte es una medida que ayuda a bajar la delincuencia.

7 ...a veces un gobierno militar puede ser preferible a uno democrático.

11 ...se debería detener por "apología del delito" a aquellos jóvenes que utilicen ropas estampadas con referencias favorables al consumo de drogas.

34 ...el Estado debería asegurar más policías en la calle para el control del crimen y la delincuencia, aún si para ello fuera necesario recortar el presupuesto de otras áreas importantes como trabajo, salud y educación.

28 ...es un problema que en nuestro país se respeten cada vez menos los símbolos patrios (bandera, himno, escarapela).

2 ...está bien que desocupados y vecinos realicen piquetes y cortes de calles o rutas, ya que es la única manera que tienen para presionar y lograr que sus reclamos sean atendidos por los gobiernos.

37 ...si una persona mata a un delincuente debería ser juzgado con el mismo trato y consideración que quien comete asesinato. 16 ...los servicios públicos esenciales (agua, luz, gas) deberían ser propiedad del Estado.

* Sub-escalas: 1 - Conservadurismo I (sexual-religioso); 2 - Progresismo I (económicomulticulturalista); 3 - Conservadurismo II (represivo-nacionalista); 4 - Progresismo II (garantista).

Fuente: Elaboración propia en base a Encuesta 2009/2010 Proyecto PID 2008 SeCyT Córdoba.

El consumo de $M M C$ se indagó a partir de respuestas abiertas a diferentes indicadores: a) tipo de soportes mediáticos (Internet, diarios, revistas, radio, TV, etc.) preferidos por los participantes para informarse sobre política (dentro de cada tipo elegido, el encuestado podía mencionar hasta tres alternativas); b) motivos principales del consumo de cada alternativa (libremente asociados); y c) percepción de la ideología política del/los medio/s preferido/s evaluada en función de la escala utilizada para valorar el auto-posicionamiento. Finalmente, se consideraron las variables socio-demográficas género, edad, nivel educativo y nivel socioeconómico (NSE). La operacionalización del NSE consideró la relación entre cantidad de aportantes y cantidad total de miembros del hogar, tomando además nivel educativo, ocupación y disposición de cobertura de salud del principal sostén del hogar e indicadores de indigencia (COMISIÓN, 2006).

Como instrumentos de recolección de datos se aplicaron encuestas estructuradas administradas de forma individual y oral por miembros del Equipo de Psicología Política, enfatizando la naturaleza voluntaria y anónima de la participación en el estudio. Los datos obtenidos fueron inicialmente sometidos a análisis univariados a los fines de conocer la distribución de las variables, re-categorizándose aquéllas que mostraron menor dispersión de 


\section{DOSSIÊ OPINIÃO PÚBLICA, ELEIÇÕES E PARTICIPAÇÃO POLÍTICA NAS DEMOCRACIAS CONTEMPORÂNEAS}

menciones (p.e., preferencias televisivas y radiales). También, las respuestas abiertas a los motivos de preferencia mediática fueron re-categorizadas en dos conjuntos básicos: atributos de cada medio elegido y valoraciones sobre la información obtenida con cada alternativa. Finalmente, se exploraron relaciones estadísticas entre las variables consideradas, estimándose en base al coeficiente $\mathrm{V}$ de $\mathrm{Cramer}^{7}$ los índices de asociación correspondientes.

\section{Resultados}

\subsection{Estructuración del consumo informativo}

Como puede observarse en el Gráfico 1, los MMC tradicionales (televisión, diarios y radio) concentran la mayor parte del consumo informativo de los participantes del estudio. Internet cuenta con una penetración relativamente menor.

Gráfico 1 - Medios utilizados para informarse sobre política

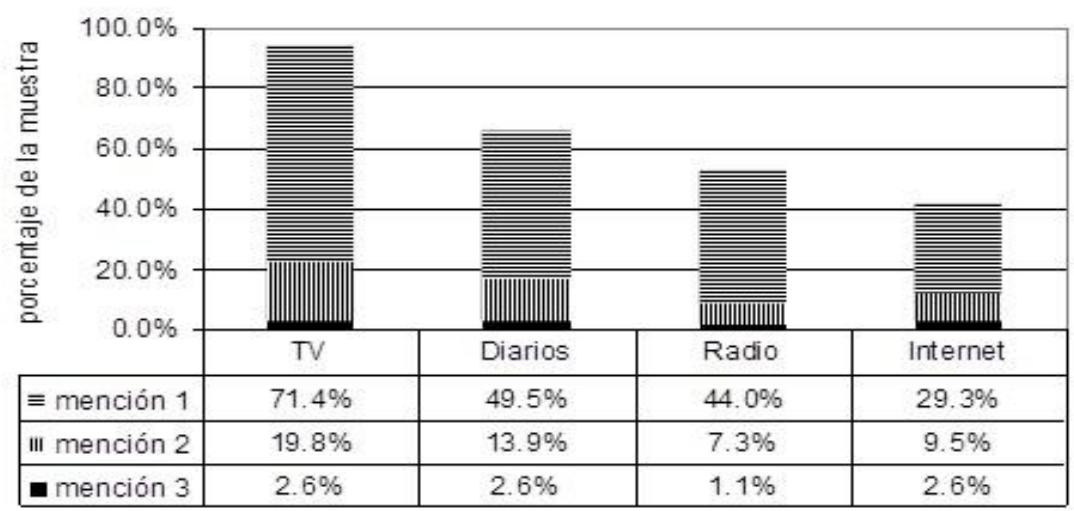

Fuente: Elaboración propia en base a Encuesta 2009/2010 Proyecto PID 2008 SeCyT Córdoba.

Respecto de las empresas mediáticas preferidas, las prácticas de consumo de los participantes tienden a la concentración en unos pocos medios. En cuanto a la televisión, la mayoría $(43,6 \%)$ prefiere "Canal 12 " señal local de programación genérica y no sólo informativa, transmitida por sistema de aire, es decir de televisión abierta - y en segundo término, se destaca el canal de noticias "TN - Todo Noticias" (11,8\%) - de cobertura

\footnotetext{
${ }^{7}$ En los resultados expuestos se considera el coeficiente $V$ de Cramer como valor estadístico de referencia respecto de la fuerza o intensidad de cada asociación establecida, valorándose su significación estadística. Dicho coeficiente es un valor estadístico sobre el grado de asociación entre variables categóricas medidas en escala nominal. Valores próximos a 0.35 y superiores indican una fuerza de asociación atendible.
} 
nacional y transmitido por sistema pre-pago. Ambos canales televisivos forman parte del multimedios Clarín. También integra este multimedios el periódico preferido por 7 de cada 10 lectores: "La Voz del interior". Este medio es el más consumido a nivel global dentro de todas las alternativas relevadas para los distintos tipos de MMC, mientras que los diarios nacionales suman en conjunto un $18,5 \%$ de las preferencias y otros diarios locales (incluyendo "Día a Día" también propiedad del multimedios Clarín) representan un $11,1 \%$ del consumo de prensa entre los participantes del estudio. Dentro de los encuestados que prefieren la radio, también se advierte una gran concentración: la cadena local LV3 ("Cadena 3") registra el 60\% de las menciones, mientras que otra frecuencia de AM (Amplitud Modulada) denominada "Mitre 810" (también del grupo Clarín) alcanza el segundo nivel de preferencias $(18,3 \%)$. Internet por su parte, cuenta con menor penetración en el circuito de prácticas de consumo de los encuestados y la diversidad de sitios relevados complejiza aún más la lectura del consumo informado en este medio. Nuevamente se advierte a "La Voz del Interior" en el primer lugar de las preferencias, cuyo sitio web concentra el $35,5 \%$ de las menciones. En segundo término, se sitúan los sitios web de los periódicos nacionales "Página 12 " (11,3\%) y "Clarín" (8,8\%). Otros sitios como blogs y páginas específicas, junto al buscador "Google" suman un $25 \%$.

Así, una caracterización genérica del circuito de prácticas de consumo informativo en Córdoba no puede obviar la preferencia generalizada por MMC con alto contenido informativo local, por sobre aquéllos de contenido nacional e internacional: esto se advierte en todos los MMC indagados, aunque en menor medida en Internet. En segundo lugar, es necesario considerar la alta concentración de consumo informativo en torno a empresas mediáticas que responden a dos grupos económicos: Clarín y Cadena 3, multimedios que en su conjunto acaparan al menos el $80 \%$ de las preferencias de los participantes del estudio. Ambos grupos mediáticos se han caracterizado en los últimos años por un fuerte enfrentamiento con la actual gestión del gobierno nacional, potenciado a partir de sus posiciones contrarias a la sanción de una nueva ley regulatoria de la propiedad mediática (Ley de Servicios de Comunicación Audiovisual). En contraste, MMC que adhieren a un discurso en favor del gobierno nacional como "Canal 10" - señal local vinculada a los servicios de radiodifusión universitarios -, "Canal 7" - canal estatal nacional, sólo accesible a través del sistema pre-pago - y el diario local "La Mañana", se ubican últimos en el orden de preferencias para cada tipo de medio.

Al profundizar en la distribución de las preferencias por tipo de medio, se destaca que la prensa, tanto en sus opciones en papel como digitales, se erige como el medio preferido para el consumo de información política, con una brecha del $13,7 \%$ respecto de la radio como otro medio tradicionalmente preferido. 


\subsection{Variables socio-demográficas vinculadas al consumo mediático}

Como se advierte en la Tabla 3 que refleja la asociación de las variables socio-demográficas con el consumo de MMC para informarse sobre política, en términos generales estas relaciones resultaron débiles (.23 a .25) aunque estadísticamente significativas $(p<.05)$ en la asociación del género con el consumo televisivo y del nivel educativo con el consumo de radio. Así, las mujeres tienden ligeramente hacia el consumo de canales locales y de televisión abierta; mientras que los varones prefieren el consumo de canales nacionales, especializados y de televisión pre-paga. En el caso de la radio, "Cadena 3 " es preferida por más de un $70 \%$ de oyentes con estudios de hasta ciclo secundario inclusive, mientras que medios asociados con el discurso oficialista (como "Radio Nacional" y "Radio Universidad") son preferidos casi con exclusividad por oyentes con estudios hasta ciclo superior.

Tabla 3 - Relación entre variables socio-demográficas y consumo de medios preferidos

\begin{tabular}{l|c|c|c|c}
\hline & TV & Diario & Radio & Internet \\
\hline Género & $.23^{*}$ & .13 & .18 & .26 \\
\hline Educación & .19 & .20 & $.25^{*}$ & $.44^{*}$ \\
\hline Edad & .23 & .27 & .26 & $.40^{*}$ \\
\hline NSE & .15 & .20 & .23 & .37 \\
\hline
\end{tabular}

Fuente: Elaboración propia en base a Encuesta 2009/2010 Proyecto PID 2008 SeCyT Córdoba.

En cuanto al nivel socio-económico (NSE) y considerando que esta variable no presenta una asociación estadísticamente significativa con el consumo televisivo, se re-categorizaron los canales preferidos en función del sistema de acceso (abierto o pre-pago), cuya asociación con el NSE también se mantuvo débil (.23) aunque resultó estadísticamente significativa $(p<$ .05). Por su parte, en el caso de Internet, el consumo se muestra significativamente asociado $(p<.05)$ al nivel educativo y la edad con buena fortaleza (entre .44 y .40). Quienes tienen un nivel educativo que alcanza el ciclo superior consumen todo tipo de medios en Internet (radiales, buscadores, diarios locales y nacionales), mientras que en aquéllos que alcanzan el ciclo secundario, las preferencias se concentran en el buscador "Google" y los sitios web de diarios locales "La Voz del Interior" o "Día a Día" ( $25 \%$ en cada caso). Asimismo, Internet aparece como único medio asociado a la edad. Sin embargo, considerando que no se distinguen asociaciones importantes entre grupos etáreos y preferencias mediáticas específicas, se trataría de una condición que - al igual que el NSE en relación con el consumo de televisión - podría operar como una suerte de barrera de acceso. 


\subsection{Motivos de las preferencias de consumo mediático}

Los motivos por los cuales los encuestados eligen consumir determinado medio por sobre otro ayudan a caracterizar cierta coherencia en la relación IP y preferencias informativas. No obstante, entre las razones atribuidas por los encuestados a sus elecciones de consumo mediático, conviven aquellas focalizadas en la evaluación de los contenidos (p.e.: el tratamiento informativo y la identificación con ciertos periodistas) con una postura ideológica más irreflexiva. Esta última se sustenta en tres motivos fundamentales vinculados con las rutinas cotidianas de los encuestados: costumbre, acceso y carácter local de la información, siendo la costumbre la razón que con mayor frecuencia se enuncia.

Además de la costumbre y el acceso, en el caso de la elección de medios televisivos se evidencia una relación estadísticamente significativa (.33) con los motivos gusto (por los contenidos ofrecidos o el formato de programación) y con la identificación personal con la figura de los periodistas. Por el contrario, en los diarios la trayectoria aparece fuertemente asociada (.49) con la elección del medio y en el caso de la radio, se advierte una menor importancia relativa del acceso como motivo de consumo mientras que el gusto, la costumbre y la identificación con los periodistas muestran una buena correlación (.42). En todos los casos, se trata de relaciones estadísticamente significativas $(p<.05)$. En relación con la televisión, el carácter local junto al volumen y al tratamiento noticioso muestran relaciones más moderadas (.46 $p<.05)$ que en la prensa $(.50 p<.05)$. Esta asociación cobra importancia en el diario "La Voz del Interior" en tanto alternativa que, como ya se señalara, registra el mayor porcentaje de preferencias en términos globales.

Interesa destacar, por último, que casi no emergen menciones sobre la IP del medio como motivo de elección entre los participantes del estudio.

\subsection{Ideología política y consumo mediático}

Como puede advertirse en los resultados presentados precedentemente, una porción importante de los ciudadanos eligen MMC sin manifestar abiertamente motivos ideológicos. No obstante, esto no implica necesariamente anular la hipótesis de una asociación positiva entre la ideología de los ciudadanos y la de los MMC que consumen. Como puede observarse en la Tabla 4, los más consumidos por los participantes del estudio para informarse (el diario La Voz del Interior, la radio Cadena 3 y los canales 12 y TN) son identificados principalmente como de centro, centro-derecha y totalmente de derecha. En oposición, el diario Página 12 y Radio Nacional son caracterizados como totalmente de izquierda o de centro izquierda.

Cabe destacar que en relación con las alternativas que lideran las preferencias dentro de los MMC tradicionales, se evidenció un porcentaje 


\section{DOSSIÊ OPINIÃO PÚBLICA, ELEIÇÕES E PARTICIPAÇÃO POLÍTICA NAS DEMOCRACIAS CONTEMPORÂNEAS}

importante de personas que no pudieron identificar la ideología del medio que consumen: televisión, más del $60 \%$; radio más del $70 \%$; y en diarios, su reconocimiento ideológico se advierte más dificultoso en el caso de su versión impresa que en su soporte digital ( $80 \%$ y $30 \%$ respectivamente).

Tabla 4 - Ideología percibida de los medios consumidos (\%)*

\begin{tabular}{|c|c|c|c|c|c|c|}
\hline \multirow{2}{*}{\multicolumn{2}{|c|}{ Medios }} & \multicolumn{5}{|c|}{ Ideología percibida de los medios } \\
\hline & & \multirow{2}{*}{\begin{tabular}{|c|}
$\begin{array}{c}\text { Totalmente } \\
\text { de izquierda }\end{array}$ \\
2,1
\end{tabular}} & \multirow{2}{*}{$\begin{array}{c}\text { Centro } \\
\text { izquierda / } \\
\text { algo de } \\
\text { izquierda }\end{array}$} & \multirow{2}{*}{\begin{tabular}{|c|} 
Centro \\
34 \\
\end{tabular}} & \multirow{2}{*}{$\begin{array}{c}\begin{array}{c}\text { Centro } \\
\text { derecha / } \\
\text { algo de } \\
\text { derecha }\end{array} \\
29,8\end{array}$} & \multirow{2}{*}{$\begin{array}{c}\text { Totalmente } \\
\text { de derecha } \\
29,8\end{array}$} \\
\hline & $\begin{array}{l}\text { La Voz del } \\
\text { Interior }\end{array}$ & & & & & \\
\hline \multirow[t]{3}{*}{ Diarios } & Clarín & 20 & -- & 20 & 40 & 20 \\
\hline & Día a Día & -- & -- & 33 & 33 & 33 \\
\hline & Página 12 & 28,6 & 71,4 & -- & -- & -- \\
\hline \multirow{3}{*}{ Radio } & Cadena 3 & -- & 2,6 & 39,5 & 28,9 & 28,9 \\
\hline & Mitre 810 & -- & 6,7 & 33,3 & 20 & 40 \\
\hline & Radio Nacional & 16,7 & 83,3 & -- & -- & -- \\
\hline \multirow{4}{*}{ TV } & Canal 10 (SRT) & 8,3 & 33,3 & 25 & 16,7 & 16,7 \\
\hline & Canal 12 & 2,9 & 5,7 & 40 & 31,4 & 20 \\
\hline & $\mathrm{TN}$ & -- & 11,1 & 27,8 & 50 & 11,1 \\
\hline & TV Pública & -- & 80 & 20 & -- & -- \\
\hline \multirow{5}{*}{ Internet } & lavoz.com.ar & -- & -- & 41,2 & 23,5 & 35,3 \\
\hline & cadena3.com.ar & -- & -- & 50 & 50 & -- \\
\hline & lanacion.com.ar & -- & -- & -- & 25 & 75 \\
\hline & pagina12.com.ar & 20 & 80 & -- & -- & -- \\
\hline & google.com.ar & -- & -- & 100 & -- & -- \\
\hline
\end{tabular}

Fuente: Elaboración propia en base a Encuesta 2009/2010 Proyecto PID 2008 SeCyT Córdoba.

Considerando el auto-posicionamiento ideológico de los participantes, se advierte que el consumo de MMC se complejiza. Como sugiere la Tabla 5, se verifica un grado de asociación atendible entre ideología y consumo (entre .31 y .34), excepto para Internet.

Los participantes que se identifican con el centro - categoría de autoposicionamiento ideológico de mayor frecuencia -, tienden a consumir medios caracterizados como de centro-derecha y totalmente de derecha. No obstante, los encuestados que se identifican como totalmente de izquierda o centroizquierda, dispersan sus prácticas de consumo informativo dentro de medios identificados con su mismo posicionamiento y también entre aquéllos mayoritariamente identificados como de centro, centro-derecha y totalmente de derecha. Así, por ejemplo, casi el $20 \%$ de los lectores de La Voz del Interior se autoposicionan en la centro-izquierda, mientras que sólo el 4,3\% del total de los lectores identificó al medio con esa posición ideológica. En 
igual sentido, mientras uno de cada 10 oyentes de Cadena 3 se identifica como totalmente de izquierda o de centro izquierda, sólo un 2,6\% de los mismos perciben que esa radio adhiera a alguna de estas posiciones. En oposición, por ejemplo, alrededor del $45 \%$ de quienes se identifican con una posición totalmente de derecha o centro-derecha como también casi el $65 \%$ de los auto-posicionados en una ideología de centro, prefieren Canal 12 como medio de información política, siendo este medio caracterizado mayoritariamente como de centro derecha y totalmente de derecha. Dentro de estos grupos no se observa el consumo de TV Pública, en tanto alternativa identificada principalmente con una ideología de centro-izquierda.

Tabla 5 - Relación entre orientaciones político-ideológicas y medios masivos consumidos

\begin{tabular}{l|c|c|c|c}
\hline & TV & Diario & Radio & Internet \\
\hline Auto-posicionamiento ideológico & $.31^{*}$ & $.34^{*}$ & $.33^{\star *}$ & .31 \\
\hline Conservadurismo sexual religioso & $.22^{* *}$ & $.26^{* *}$ & $.30^{*}$ & .34 \\
\hline Progresismo multiculturalista & .15 & .17 & $.25^{\star *}$ & $.44^{\star *}$ \\
\hline Conservadurismo represivo nacionalista & $.23^{* *}$ & $.34^{\star}$ & $.29^{*}$ & .33 \\
\hline Progresismo garantista & .17 & $.26^{* \star}$ & $.24^{* \star}$ & .36 \\
\hline \multicolumn{2}{c}{$\mathrm{p}<.001 \mathrm{y}^{* *} \mathrm{p}<.05$}
\end{tabular}

Fuente: Elaboración propia en base a Encuesta 2009/2010 Proyecto PID 2008 SeCyT Córdoba.

Por último, desde una perspectiva centrada en el posicionamiento valorativo y actitudinal de los encuestados frente a issues políticos relevantes, se profundiza el vínculo entre sus orientaciones ideológicas y elecciones mediáticas. En este sentido, en la Tabla 5 se observan relaciones moderadas (.22 a .34) y estadísticamente significativas entre el conservadurismo represivo nacionalista, el conservadurismo sexual religioso y el consumo de los tres MMC tradicionales (TV, diarios y radio). Asimismo, se observa que los progresistas multiculturalistas se asocian significativamente el consumo de diarios y radio (.24 a .26), en tanto los progresistas garantistas se relacionan prioritariamente con el consumo de Internet (.45). Dentro de las orientaciones ideológicas conservadoras en lo sexual y religioso, el consumo de televisión se concentra sobre Canal 12 - entre el 60 y $80 \%$ del nivel "medio" y "medio alto" de esta dimensión ideológica. Este esquema se reitera entre los conservadores de tipo represivo-nacionalista, manteniéndose ausente la TV Pública entre aquéllos de nivel más alto y dándose una mayor diversificación de las preferencias entre aquéllos de nivel más bajo en la escala.

En cuanto al consumo de diarios, entre ambos tipos de conservadores resulta indiscutible el liderazgo de La Voz del Interior como medio que concentra un $75 \%$ de las preferencias, alcanzando incluso el $95 \%$ entre los conservadores represivo-nacionalistas. A medida que se fortalece el nivel de los conservadurismos relevados, más concentrado se observa el consumo en 


\section{DOSSIÊ OPINIÃO PÚBLICA, ELEIÇÕES E PARTICIPAÇÃO POLÍTICA NAS DEMOCRACIAS CONTEMPORÂNEAS}

torno a diarios locales, mientras a menores indicadores se advierte menos homogeneidad y una mayor preferencia por diarios nacionales. En el caso de la radio, entre los indicadores altos y medios de ambos tipos de conservadurismo también se excluyen aquellas alternativas informativas predominantemente asociadas con ideologías de izquierda.

Respecto de la asociación de las orientaciones ideológicas progresistas (multiculturalista y garantista) con el consumo mediático, en general y a diferencia de lo ocurrido con las orientaciones conservadoras, se observa la emergencia de relaciones de menor fuerza y en ocasiones no significativas respecto de los medios tradicionales. Asimismo, su consumo se diversifica incluyendo de forma simultánea diarios como La Voz del Interior, Clarín y Página 12 o radios como Cadena 3, Mitre 810 y Radio Nacional.

\section{Conclusiones}

Se evidencia una tendencia generalizada entre los ciudadanos cordobeses hacia un esquema concentrado de consumo de información política - en cuanto al tipo de medio y las empresas mediáticas elegidas -, en tanto modelo que reproduce los parámetros de selectividad y competencia impuestos por el propio mercado mediático. Esto podría vincularse con el hecho que en Argentina, la economía política de la información es una problemática que se ha instalado con fuerza en la agenda pública desde fines de 2009. Con la sanción de la ley de comunicación antes mencionada, se abre un debate social sobre la operación económica e ideológica de los grupos mediáticos hegemónicos, coincidente con la finalización del trabajo de campo de esta investigación. Al respecto, las principales empresas mediáticas preferidas por los encuestados (Cadena 3 y Grupo Clarín) poseen una postura ideológica explícitamente contraria al gobierno nacional. Así, corroboramos los argumentos de Moreno García (2007) sobre la constitución de los MMC como espacios para la confrontación ideológica. De hecho, las opciones mediáticas consumidas se polarizan en medios pro y anti gobierno nacional, con lo cual en alguna medida la disputa mantiene una lógica dualista, obturando la aparición y circulación de mensajes que diversifiquen el escenario.

Por otra parte, la presencia de la prensa como medio de mayor centralidad en el consumo de información política a nivel global, va en la línea de lo ya constatado por Fara (2004) y Martínez Pandiani (2007) respecto a la importancia local de este tipo de medio. Otro aspecto a resaltar en este sentido, lo constituye el hecho de que la radio e Internet se destacan como los únicos MMC cuyo consumo puede asociarse significativamente al nivel educativo de la población. Ya Garret y Danzinger (2011) corroboraban esta relación en el caso de Internet y a su vez Jerez, Sampedro y Baer (2000) asociaban esta situación con la tesis de la distancia social en el acceso a la información.

En cuanto a los motivos enunciados por los participantes al momento 
de elegir, el carácter local de la información emerge como criterio preferencial y podría ser entendido como práctica asociada la preservación del vínculo comunitario (CANTÚ, 2006). No obstante, este hecho puede ser también vinculado con variables socio-demográficas. La disponibilidad de servicios de televisión abierta o pre-paga operaría como una barrera de acceso económica, puesto que sólo quiénes pagan por un servicio privado pueden trascender las fuentes locales y consultar canales nacionales e internacionales sobre temas de interés o actualidad. En coincidencia con estudios previos (KNOBLOCHWESTERWICK, BRÜCK y HASTALL, 2006; LOZANO RENDÓN, 2003), Ios resultados aquí presentados señalan que también el género estaría asociado a las prácticas de consumo mediático de información política local, mostrando que las mujeres se vinculan más con este tipo de noticias. Asimismo, otras dos razones principalmente enunciadas se vinculan con las rutinas informativas relevadas: costumbre y acceso. Si bien esta situación puede ser comprendida desde la vertiente culturalista como un hábito adquirido y una práctica ritual (CANTÚ, 2006; CHRISTENSEN, 2006), las razones de selectividad de las audiencias también podrían vincularse con otros aspectos psico-políticos que trascienden lo expresamente manifiesto en el discurso de los participantes.

De hecho, si bien no se enuncia a la IP del medio como razón para elegirlo, en contraste se observa que los participantes del estudio efectúan una exposición selectiva ideológicamente motivada. Se advierte que las personas que se auto-posicionan como de derecha o centro, a la vez que las que registran niveles altos de conservadurismo sexual-religioso y nacionalista represivo, consumen exclusivamente medios que identifican como de derecha. Esto refuerza los resultados de estudios que sugieren el empleo de la IP como método heurístico de evaluación que anticipa las decisiones de exposición de las audiencias (TURNER, 2007; IYENGAR y HAHN, 2009; STROUD, 2008) y podría estar vinculado con los nuevos abordajes de la tesis de la disonancia cognitiva. Sin embargo, la situación de las personas autoposicionadas a la izquierda e identificadas con posiciones progresistas, complejiza el análisis. Éstas muestran un consumo diversificado en términos ideológicos, no restringido a informaciones coincidentes con sus posturas. Esto indicaría que la tesis de la disonancia cognitiva precisa ser complementada con aportes que desde otras teorías que permitan comprender este hecho. Al respecto, quizás la teoría de la personalidad nos posibilite echar luz sobre este fenómeno. Sus señalamientos podrían explicar no sólo el consumo diversificado ideológicamente que efectúan las personas de izquierda y progresistas de nuestro estudio - junto a su mayor uso de Internet -, sino también la tendencia de las personas de derecha a consumir sólo medios con los que sienten coincidir. Esta tendencia de las personas caracterizadas como conservadoras, requiere asimismo una reflexión en términos políticos. En esa línea, Garret (2006) planteaba el peligro que estas posturas suponen para la consolidación de una democracia deliberativa y su severo impacto sobre la 


\section{DOSSIÊ OPINIÃO PÚBLICA, ELEIÇÕES E PARTICIPAÇÃO POLÍTICA NAS DEMOCRACIAS CONTEMPORÂNEAS}

\section{tolerancia política.}

Finalmente, es notable el gran porcentaje de personas que no pudieron identificar la ideología del medio que consumen. Desde un marco de comprensión proporcionado por la vertiente culturalista, la construcción de hábitos y la proliferación de rituales en torno al consumo mediático podría implicar una naturalización que impida acceder a una postura reflexiva sobre los posicionamientos ideológicos que transmiten los MMC. Lo llamativo al respecto es que son precisamente los medios más consumidos (Cadena 3, Canal 12, La Voz del Interior) y caracterizados como opositores a la gestión del gobierno nacional, los que recogen mayores porcentajes de preferencia entre personas que no logran auto-posicionarse ideológicamente. Frente a esta situación, se impone un trabajo de de-construcción de los propios hábitos de consumo mediático, que permita la conformación de experiencias críticas y reflexivas en torno a los procesos de información política de estas audiencias.

Silvina Brussino es Doctora en Psicología (Universidad Nacional de Córdoba UNC), miembro de la Carrera de Investigador Científico y Tecnológico de CONICET, ex-Presidenta de la Asociación Argentina de Ciencias del Comportamiento, perteneciente a la International Union of Psychological Science.

E-mail: brussino@psyche.unc.edu.ar

Ana Pamela Paz García es Licenciada en Relaciones Públicas e Institucionales (Universidad Siglo 21), Magíster en Sociología y Doctoranda en Estudios Sociales de América Latina, mención Sociología (CEA-UNC), Becaria de Postgrado de CONICET - CIECS (Centro de Investigaciones y Estudios sobre Cultura y Sociedad).

E-mail: pamela.pazgarcia@gmail.com

Hugo H. Rabbia es Licenciado en Relaciones Internacionales (Universidad Católica de Córdoba), Máster Europeo en Estudios Latinoamericanos (Universidad Autónoma de Madrid, España y Université Toulousse Le-Mirail, Francia), Doctorando en Estudios Sociales de América Latina, mención Sociología, Becario de Postgrado de CONICET.

E-mail: hrabbia@gmail.com

Débora Imhoff es Licenciada en Psicología y Doctoranda en Psicología (UNC), Becaria de Postgrado de CONICET, miembro de la Secretaría de Formación, Investigación y Estadística de la Central de los Trabajadores Argentinos, sede Córdoba Capital.

E-mail: dimhoff@psyche.unc.edu.ar 


\section{Referencias}

AARTS, Henk; VERPLANKEN, Bas; VAN KNIPPENBERG, Ad. Predicting Behavior From Actions in the Past: Repeated Decision Making or a Matter of Habit? Journal of Applied Social Psychology, Nijmegen, v. 28, n. 15, p. 1355-1374, aug. 1998.

ALAMINOS, Antonio; FRANCÉS, Francisco; SANTACREU, Óscar. Socialización, ideología y participación. Casos prácticos de análisis estructural de covarianzas. 2005. Disponible en: <http://www.obets.ua.es>. Acceso en: 03 ago. 2011.

ALESSANDRO, Martín. Clivajes sociales, estrategias de los actores y sistema de partidos: la competencia política en la Ciudad de Buenos Aires (19952005). Revista SAAP, Buenos Aires, v. 3, n. 3, p. 581-614, jul.-dic. 2009.

APARICIO, Miriam. Cultura institucional y homogeneización mental: un análisis de impacto en universitarios. Interdisciplinaria, Buenos Aires, v. XXII, n. 2, p. 123-154, ago.-dic. 2005.

BRUSSINO, Silvina; et al.. Dimensión Operativa de la Ideología Política en ciudadanos de Córdoba/Argentina. Revista Psicología Política, Valencia, n. 43, p. 85-106, nov. 2011. Disponible en: <http://www.uv.es/garzon/psicologia\%20politica/ N43-4.pdf>. Acceso en: 23 nov. 2011.

BRUSSINO, Silvina; RABBIA, Hugo; HÜG, Mercedes. Abordaje psicosocial de la participación política en la ciudad de Córdoba. En: CONGRESO INTERAMERICANO DE PSICOLOGÍA, XXIX, 2003, Lima/Perú. Anais... Disponible en: <http//:psychepolitica.wordpress.com>. Acceso en: 23 nov. 2011.

CANTÚ, Ariadna. Informaciones de los medios: ¿Un consumo ritualizado?. In: JORNADAS NACIONALES DE INVESTIGADORES EN COMUNICACIÓN, 10., 2006, San Juan, Argentina. Memorias .... Disponible en: <http://wwwredcomunicaion.org/memorias/p_jornadas_p.php?od=754\&idj=5 >. Acceson en: 13 dic. 2011.

CASE, Donald; ANDREWS, James E.; JOHNSON, J. David; ALLARD, Suzanne L. Avoiding versus seeking: the relationship of information seeking to avoidance, blunting, coping, dissonance, and related concepts. Journal of the Medical Library Association, Bethesda/ MD, v. 93, n. 3, p. 353-362, july 2005.

CATTERBERG, Edgardo; BRAUN, María. ¿Izquierda y derecha en la opinión 
DOSSIÊ OPINIÃO PÚBLICA, ELEIÇÕES E PARTICIPAÇÃO POLÍTICA NAS DEMOCRACIAS CONTEMPORÂNEAS

pública argentina? 1989. (Crítica y Utopía, n. 18) Disponible en: <http://www.escenariosalternativos.org >. Acceso en: 23 nov. 2011.

CHRISTENSEN, Lars. Understanding the domestication of interactive television through narrative interviews. En: CONGRESO "MEDIA USE AND SELECTIVITY - NEW APPROACHES TO EXPLAINING AND ANALYSING AUDIENCES", 2006, Erfurt. Memorias..., p. 23-25, 2006

COMISIÓN DE ENLACE INSTITUCIONAL, AAM-SAIMO-CEIM. NSE 2006. Antecedentes, marco conceptual, enfoque metodológico y fortalezas. 2006.

CONVERSE, Philip. The nature of belief systems in mass publics. Critical Review, Helotes, TX, v. 18, n. 1-3, p. 1-74, mar. 2006

D'ADAMO, Orlando; FREIDENBERG, Flavia; GARCÍA BEAUDOUX, Virginia. Medios de comunicación de masas y establecimiento de la agenda: un estudio empírico en Argentina. Revista América Latina Hoy, Salamanca, v. 25, p. 5766 , ago. 2000.

D'ADAMO, Orlando; GARCÍA BEAOUDOUX, Virginia. Derecha e izquierda, ¿dos cajas vacías?. En: OBLITAS, Luis; RODRÍGUEZ KAUTH, Ángel (Comps.). Psicología Política. Col. San Rafael: Plaza y Valdés, 1999. p. 197-217.

D'ALESSIO, Dave; ALLEN, Mike. The selective exposure hypothesis and media choice processes. En: PREISS, Raymond et al. (Eds.). Mass Media Effects Research: Advances Through Meta-Analysis. New Jersey: Lawrence Erlbaum Associates Inc., 2007. p. 103-117.

DUFF, Jeremy. The reciprocal effects of Ideology and Issue Positions: Considering a directional link from Issues to Ideology". En: ANNUAL MEETING OF THE AMERICAN POLITICAL SCIENCE ASSOCIATION, 103., 2007, Chicago. Memorias ..., 2007. p. 2-45

ELLIS, Christopher; STIMSON, James. Operational and symbolic ideology in the American Electorate: the paradox revisited. En: ANNUAL MEETING OF THE MIDWEST POLITICAL SCIENCE ASSOCIATION, 63., 2005, Chicago. Memorias..., 2005. p. 1-57.

FARA, Carlos. Comunicación política en América Latina: tendencias, factores y problemas prácticos. Diálogo político, Buenos Aires, v. XXII, n. 1, p. 79-99, mar. 2004.

FEDERICO, Christopher; GOREN, Paul. Motivated social cognition and ideology: is attention to elite discourse a prerequisite for epistemically 
motivated political affinities?. En: JOST, John; KAY, Aaron C.; THORISDOTTIR, Hulda (Orgs.). Social and Psychological Bases of Ideology and System Justification. Princeton: Oxford, 2009. cap. 11.

GARCÍA CANCLINI, Néstor. Ideología y Cultura. Buenos Aires: UBA-FFyL, 1984.

GARRET, Kelly. Seeking Similarity, Not Avoiding Difference: Reframing the Selective Exposure Debate. En: ANNUAL CONFERENCE OF THE INTERNATIONAL COMMUNICATION ASSOCIATION, 56., 2006, Dresden, Germany. Memorias..., 2006. p. 35-54.

GARRET, Kelly; DANZINGER, James. The Internet Electorate. Communications of the ACM, New York, v. 54, n. 3, p. 117-123, mar. 2011.

GERBER, Alan; HUBER, Gregory A.; DOHERTY, David; DOWLING, Conor M. Personality Traits and the Consumption of Political Information. American Politics Research, Illinois, v. 39, n. 1, p. 32-84, jan. 2011.

GRAF, Joseph; ADAY, Sean. Selective Attention to Online Political Information. Journal of Broadcasting \& Electronic Media, Washington DC, v. 52, n. 1, p. 86100, mar. 2008

HOLBERT, R. Lance; GARRETT, Kelly; GLEASON, Laurel. A new era of Minimal Effects? A Response to Bennet and Iyengar. Journal of Communication, Hoboken, v. 60 , n. 1, p. 15-34, mar. 2010

INDEC. Censo Nacional Oficial. 2010. Disponible en: <http.//www.censo2010.index.gov.ar>. acceso em 20 dic. 2011.

IYENGAR, Shanto; HAHN, Kyu. Red Media, Blue Media: Evidence of Ideological Selectivity in Media Use. Journal of Communication, Hoboken, v. 59, n. 1, p. 19-39, mar. 2009

JEREZ, Ariel; SAMPEDRO, Victor; BAER, Alejandro. Medios de comunicación, consumo informativo y actitudes políticas en España. Madrid: CIS, 2000.

JACOBY, William. Ideological identification and issue attitudes. American Journal of Political Science, Houston, v. 35, n. 1, p. 178-205, feb. 1991.

JOST, John. The end of the end of ideology. American Psychologist, Washington DC, v. 61, n 7, p. 651-670, oct. 2006.

JOST, John; FEDERICO, Christopher; NAPIER, Jaime. Political ideology: Its 
structure, functions, and elective affinities. Annual Review of Psychology, Palo Alto, n. 6, p. 307-337, 2009.

KINDER, Donald. Commnunication and Politics in the Age of Information. En: SEARS, David; HUDDY, Leonie; JERVIS, Robert (Eds.). Oxford Handbook of Political Psychology. New York: Oxford University Press, 2003. p. 357-393.

KNOBLOCH-WESTERWICK, Silvia; BRÜCK, Julia; HASTALL, Matthias. The gender news use divide: Impacts of sex, gender, self-esteem, achievement, and affiliation motive on German newsreaders' exposure to news topics. Communications, Hoboken, v. 31, n. 3, p. 329-345, sep. 2006

LAU, Richard; REDLAWSK, David. How voters decide. Information processing during election campaigns. Cambridge: Cambridge University Press, 2006.

LOHR, Sharon. Muestreo: diseño y análisis. México, D.F.: International Thomson, 2000.

LOZANO RENDÓN, José. Consumo y lecturas negociadas de noticieros televisivos en Monterrey, Guadalajara y México DF. Estudios sobre las Culturas Contemporáneas, Colima, v. IX, n. 18, p. 43-56, dic. 2003.

MARTÍNEZ PANDIANI, Gustavo. Marketing político: campañas, medios y estrategias electorales. Buenos Aires: Ugerman Editor, 2007.

MATTELART, Armand; MATTELART, Michèle. Historia de las teorías de la comunicación. Barcelona: Paidós, 1997.

MCQUAIL, Denis. With More Hindsight: Conceptual Problems and Some Ways Forward for Media Use Research. Communications, Hoboken, v. 26, n. 4, p. 337-350, jan. 2001.

MORENO GARCÍA, Alejandro. Un proyecto de medición del nivel de aceptación de la ideología de los grupos dominantes. Discurso y Sociedad, Barcelona, v. 1, n. 3, p. 482-511, 2007.

NAFSTAD, Hilde E.; BLAKAR, Rolv M.; CARLQUIST, Erik et al. Ideology and power: the influence of current neo-liberalism in society. Journal of Community \& Applied Social Psychology, Hoboken, v. 17, n. 4, p. 313-327, jul.-aug. 2007.

NORRIS, Pippa. A Virtuous Circle? The Impact of Political Communications in Post-Industrial Democracies. Revised version for the PSA Yearbook. 2004. Disponible en: 
<http://www.hks.harvard.edu/fs/pnorris/Acrobat/PSA2000\%20Yearbook.pdf > Acceso en: 23 nov. 2011.

PAZ GARCÍA, Ana Pamela. Opinión pública, mediatización y representación democrática: la conflictiva construcción de horizontes colectivos de sentido. Intersticios. Revista Sociológica de Pensamiento Crítico, Madrid, v. 2, n. 2, p. 197-210, jul. 2008.

- Dinámica contemporánea de la Opinión Pública (2009-2011). Procesos mediatizados de información política de los ciudadanos cordobeses. 2011. 255 f. Tesis (Doctorado en Estudios sociales de América Latina Mención Sociología) [inédita] - Centro de Estudios Avanzados, Universidad Nacional de Córdoba, [2011].

SCHWEIGER, Wolfgang. Trans-Media Use-Styles: Empirical Evidence of a New Concept". En: CONGRESO "MEDIA USE AND SELECTIVITY - NEW APPROACHES TO EXPLAINING AND ANALYSING AUDIENCES", 2006, Erfurt. Memorias..., 2006. p. 6-8.

SEARS, David; FREEDMAN, Jonthan. Selective exposure to information: A critical review. Public Opinion Quarterly, Deerfield, v. 31, n. 2, p. 194-213, summer 1967

SENI-MEDINA, Giuliano. El discurso político desde la publicidad de consumo en la televisión. Palabra Clave, Chía, v. 14, n. 1, p. 123-135, jun. 2011

STEMPEL, Guido. Selectivity in readership of political news. Public Opinion Quarterly, Deerfield, v. 25, n. 3, p. 400-404, autumn 1961.

STROUD, Natalie. Media use and political predispositions: revisiting the concept of selective exposure. Political Behavior, Norwell, v. 30, n. 3, p. 341366, sep. 2008

TCACH, César. Pensar Córdoba: reflexiones preliminares. Estudios, Córdoba, v. 15 , p. 9-14, 2004.

. Sabattinismo y peronismo. Partidos políticos en Córdoba 1943-1955. Buenos Aires: Editorial Sudamericana, 1991.

TORO TAMAYO, L. C. Publicidad mediática. Acercamiento a la relación publicidad e ideología. Mediaciones Sociales. Revista de Ciencias Sociales y de la Comunicación, Madrid, n. 3, p. 241-265, II sem. 2008. Disponible en: <http://www.ucm.es/info/mediars>. Acceso en: 03 ago.2011. 
DOSSIÊ OPINIÃO PÚBLICA, ELEIÇÕES E PARTICIPAÇÃO POLÍTICA NAS DEMOCRACIAS CONTEMPORÂNEAS

TURNER, Jel. The messenger overwhelming the message: ideological cues and perceptions of bias in television news. Political Behavior, Norwel, v. 29, n. 4, p. 441-464, dec. 2007.

VAGGIONE, Juan Marcos; BRUSSINO, Silvina. El apartidismo y el apolitisismo. Un análisis a partir de la sensación de falta de poder. Anuarios CIJS, Córdoba, sección 3, p. 307-320, 1997.

ZECHMEISTER, Elizabeth. Qué es la izquierda y quién está a la derecha en la política mexicana. Un enfoque con el método $\mathrm{q}$ al estudio de las etiquetas metodológicas. Política y Gobierno, México, D.F., v. XIII, n. 1, p. 51-98, I sem. 2006.

Texto recebido em 26/08/2011.

Aprovado em 15/12/2011. 